\title{
Jejunostomy at the time of esophagectomy is associated with improved short-term perioperative outcomes: analysis of the NSQIP database
}

\author{
Michael Watson ${ }^{1}$, Sally Trufan ${ }^{2}$, Jennifer H. Benbow ${ }^{3}$, Nicole L. Gower ${ }^{3}$, Joshua Hill ${ }^{1}$, Jonathan C. Salo ${ }^{1}$ \\ ${ }^{1}$ Levine Cancer Institute, Division of Surgical Oncology, ${ }^{2}$ Department of Biostatistics, Levine Cancer Institute, ${ }^{3}$ LCI Research Support, Clinical \\ Trials Office, Levine Cancer Institute, Carolinas Medical Center, Atrium Health, Charlotte, NC, USA \\ Contributions: (I) Conception and design: M Watson, NL Gower, J Hill, JC Salo; (II) Administrative support: None; (III) Provision of study materials \\ or patients: None; (IV) Collection and assembly of data: M Watson, S Trufan, NL Gower, JC Salo; (V) Data analysis and interpretation: S Trufan, JC \\ Salo; (VI) Manuscript writing: All authors; (VII) Final approval of manuscript: All authors. \\ Correspondence to: Jonathan C. Salo, MD. Division of Surgical Oncology, Department of Surgery, Levine Cancer Institute, Carolinas Medical Center, \\ 1021 Morehead Medical Drive, Charlotte, NC 28204, USA. Email: Jonathan.Salo@AtriumHealth.org.
}

\begin{abstract}
Adequate preoperative and perioperative nutrition has been shown to improve outcomes for patients undergoing esophagectomy. The most effective way to provide enteral nutrition for patients after esophagectomy is via jejunostomy tube. There is an open debate whether a feeding jejunostomy tube is necessary at the time of esophagectomy. This study evaluated short term surgical outcomes for patients undergoing esophagectomy with and without concurrent jejunostomy tube placement. Esophageal cancer patients were identified from the NSQIP database who underwent esophagectomy between 2005 through 2016. Patients were classified into 2 cohorts: patients with concurrent jejunostomy tube placement and those without jejunostomy placement at the time of esophagectomy. Clinical and demographic data was collected. Differences in short term outcomes were assessed by univariate and multivariable analysis, including prolonged hospital stay (>30 days), in-hospital mortality, and 30-day mortality for both cohorts. We identified 8,632 patients that underwent esophagectomy for esophageal cancer with $80 \%$ males and mean age of $63.2 \pm 10.6$ years. Twenty percent $(n=1,723)$ had preoperative weight loss in the 6 -month period preceding surgery. Forty-five percent $(n=3,900)$ patients had jejunostomy placement at the time of esophagectomy. Overall, the rate of prolonged hospital stay $(\mathrm{P}=0.006)$, in-hospital mortality $(\mathrm{P}<0.001)$ and 30 -day mortality $(\mathrm{P}<0.001)$ were significantly higher in patients without concurrent jejunostomy in both univariable and multivariable models. This study demonstrates that patients with jejunostomy placement at the time of esophagectomy have improved short term perioperative outcomes.
\end{abstract}

Keywords: Esophagectomy; jejunostomy; esophageal cancer; short-term outcomes

Submitted Nov 18, 2019. Accepted for publication Feb 05, 2020.

doi: 10.21037/jgo.2020.02.06

View this article at: http://dx.doi.org/10.21037/jgo.2020.02.06

\section{Introduction}

The incidence of esophageal cancer has been steadily increasing with an estimated 17,650 newly diagnosed cases and 16,080 esophageal cancer related deaths expected for 2019 in the United States, alone (1). Worldwide, the incidence is estimated to be 572,000 new cases annually with 508,600 deaths (2). Surgical resection is the cornerstone of treatment for patients with resectable tumors. Patients with preoperative malnutrition and poor preoperative function have worse outcomes after esophagectomy (3-5). Weight loss and malnutrition related to dysphagia, odynophagia, and early satiety can occur in up to $60 \%$ of esophageal cancer patients (6-8). Additionally, pretreatment malnutrition is a prognostic factor for patients 
undergoing neoadjuvant or definitive chemoradiotherapy for esophageal cancer (9). It has been demonstrated that optimization of preoperative nutrition for patients undergoing chemoradiotherapy increases tolerance of treatment, reduces weight loss, and hospital admissions (10-12). Similarly, studies have demonstrated that early enteral feeding after esophagectomy have shown improved outcomes for patients with esophageal cancer (13-17).

Jejunostomy tube can be placed effectively preoperatively or at the time of esophagectomy. Preoperative jejunostomy tube placement allows for preoperative nutritional optimization, however this requires the patient to undergo an additional procedure prior to esophagectomy. For patients able to maintain adequate nutrition preoperatively, this confers the risk of surgery without a benefit in the preoperative period. Placing a jejunostomy tube at the time of esophagectomy does not subject a patient to an additional procedure while also securing a route of enteral feeding for the postoperative period. After esophagectomy, patients have a limited ability to maintain adequate oral intake, with one study demonstrating a median of $60 \%$ caloric intake on postoperative day 5 (18). Which patients will have difficulties with postoperative nutrition remains unclear, and the optimal time for jejunostomy tube placement for esophagectomy is still under debate. The aim of this study was to evaluate the effect of jejunostomy tube placement at the time of esophagectomy on length of stay, mortality, and discharge destination using a large national database.

\section{Materials and methods}

Using the NSQIP database from 2005 through 2016, we identified patients with esophageal cancer that underwent esophagectomy based on CPT coding (43107, 43108, 43112, 43113, 43116, 43117, 43118, 43121, 43122, 43123, 43124, $43289,43360)$. These patients were divided into two groups: patients with concurrent jejunostomy tube placement (CPT codes 44015 and 44186) and those without jejunostomy placement at the time of esophagectomy. Descriptive statistics for demographic data (sex, age), perioperative comorbidities (dyspnea, chronic obstructive pulmonary disease (COPD), diabetes, ascites, dialysis), American Society of Anesthesiologists (ASA) classification, disseminated cancer per ACS-NSQIP guidelines (19), presence of preoperative weight loss, and anastomotic location were performed and differences between jejunostomy groups was evaluated. Using univariate logistic regression analysis, the risk of adverse short-term outcomes including prolonged hospital stay ( $>30$ days), in-hospital mortality, and 30-day mortality for both groups was assessed for each predictive variable. Predictors that were significant at $\mathrm{P}<0.10$ in univariable models were included in the adjusted multivariable logistic regression analyses. Significance for multivariable analyses was set at $\mathrm{P}<0.05$. All analyses were conducted using SAS 9.4 (SAS Inc., Cary, NC).

\section{Results}

There were 8,632 [6,869 (79.6\%) male] patients identified that underwent esophagectomy for esophageal cancer with an average age of $63.2 \pm 10.6$ years. Patient demographics and characteristics are listed in Table 1. We identified 3,900 (45.2\%) patients with jejunostomy tube placement at the time of esophagectomy. There were 1,723 patients that presented with preoperative weight loss $>10 \%$ body weight in the six months preceding surgery. Of these patients, $731(42.4 \%)$ had jejunostomy tube placement at the time of esophagectomy. There were differences in presence of dyspnea, disseminated cancer, preoperative weight loss, rate of cervical anastomosis, rate of thoracotomy, and location of anastomosis between patients with and without concurrent jejunostomy placement.

Outcomes for patients with and without concurrent jejunostomy tube placement are listed in Table 2. Overall, rate of prolonged hospital stay was $5.9 \%$, with rates of $5.0 \%$ for patients with concurrent jejunostomy and $6.6 \%$ for patients without concurrent jejunostomy (Chi square $=7.5$, $\mathrm{P}=0.006)$. The rate of in-hospital mortality for all patients was $7.4 \%$, with rates of $6.1 \%$ for patients with concurrent jejunostomy and $8.4 \%$ for patients without jejunostomy (Chi square $=16.3, \mathrm{P}<0.001$ ). The rate of 30-day mortality was $2.9 \%$ overall, with rates of $2.2 \%$ for patients with concurrent jejunostomy and $3.5 \%$ for patients without concurrent jejunostomy (Chi square $=12.6, \mathrm{P}<0.001$ ).

Analysis of factors associated with 30-day mortality are listed in Table 3. Univariable analysis demonstrated that age $(\mathrm{P}<0.001)$, COPD $(\mathrm{P}<0.001)$, ASA classification III $(\mathrm{P}=0.002)$, ASA classification IV $(\mathrm{P}<0.001)$, ASA classification $\mathrm{V}(\mathrm{P}<0.001)$, ascites $(\mathrm{P}<0.001)$, noninsulin-dependent diabetes $(\mathrm{P}=0.015)$, dialysis $(\mathrm{P}<0.001)$, disseminated cancer $(\mathrm{P}<0.001)$, moderate dyspnea $(\mathrm{P}<0.001)$, dyspnea at rest $(\mathrm{P}=0.005)$, and concurrent jejunostomy tube (OR 0.62; 0.48-0.81; $\mathrm{P}<0.001)$ were associated with 30-day mortality. Multivariable analysis demonstrated that age $(\mathrm{P}<0.001)$, ASA classification IV $(\mathrm{P}<0.001)$, ASA classification $\mathrm{V}(\mathrm{P}=0.009)$, ascites $(\mathrm{P}=0.015)$, dialysis 
Table 1 Demographics and characteristics of esophagectomy patients with jejunostomy tube

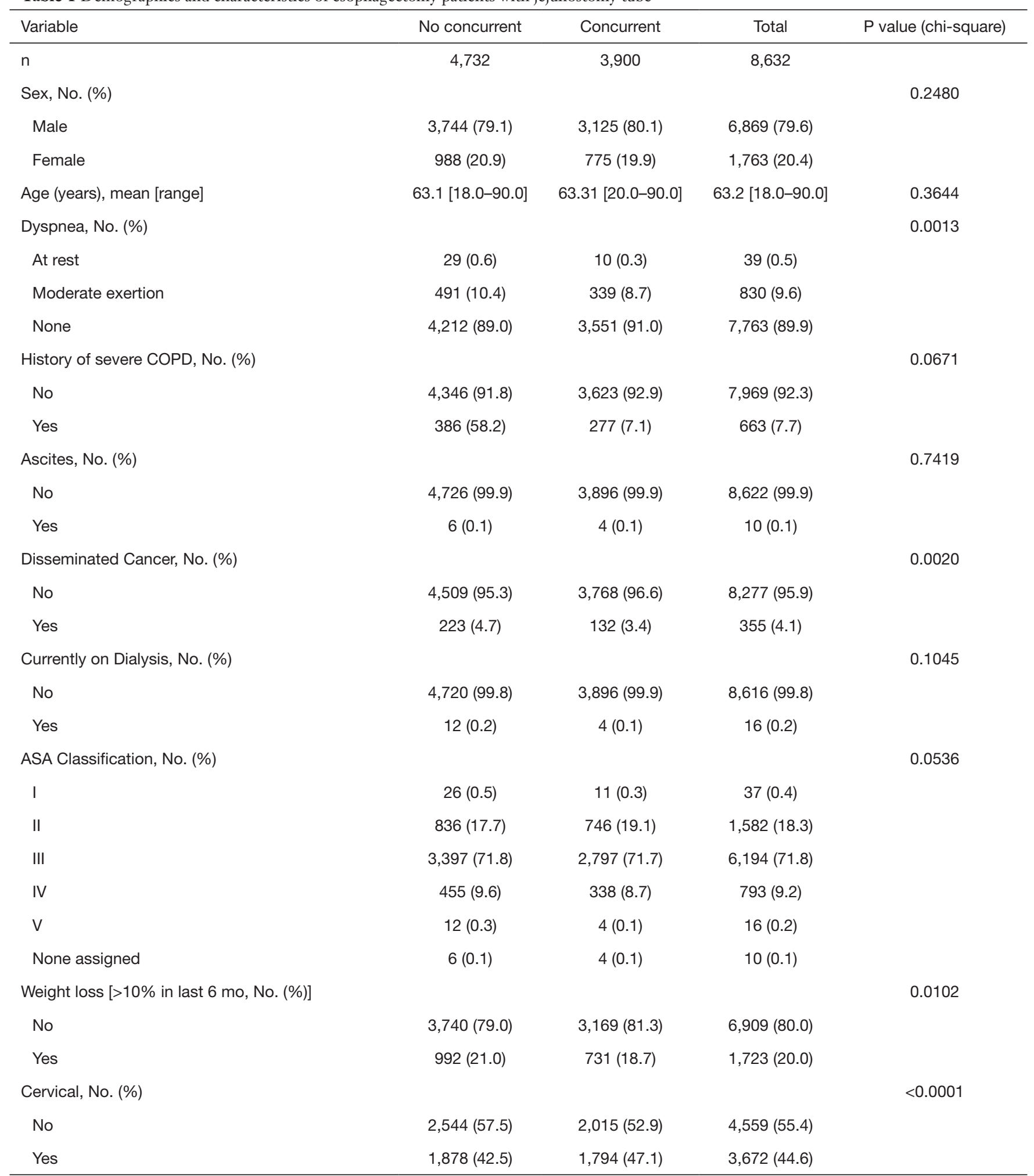

Table 1 (continued) 
Table 1 (continued)

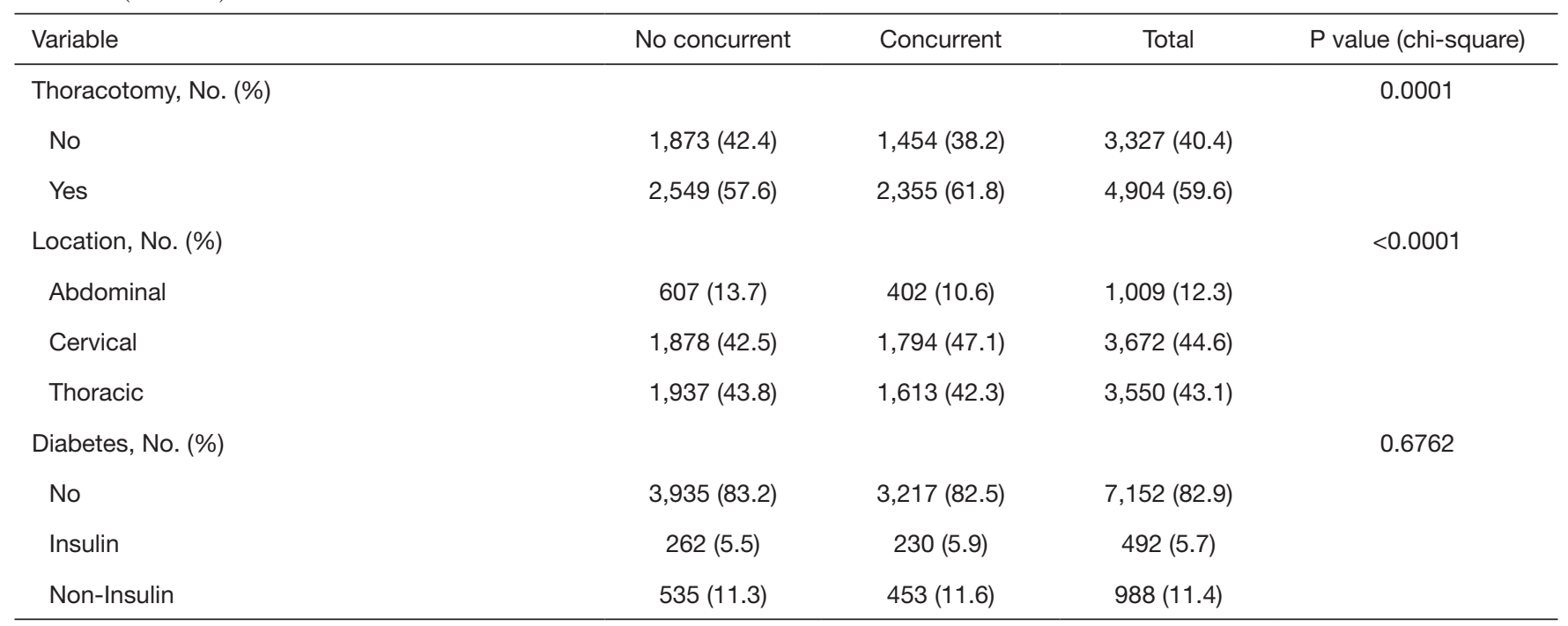

COPD, chronic obstructive pulmonary disease; ASA, American Society of Anesthesiologists.

Table 2 Outcomes of esophagectomy patients undergoing jejunostomy tube placement

\begin{tabular}{|c|c|c|c|c|}
\hline Variable & No concurrent & Concurrent & Total & $P$ value \\
\hline No & $3,247(93.4)$ & $2,866(95.0)$ & $6,113(94.1)$ & \\
\hline Yes & $231(6.6)$ & $152(5.0)$ & $383(5.9)$ & \\
\hline In hospital mortality, No. (\%) & & & & $<0.001$ \\
\hline Yes & $398(8.4)$ & $239(6.1)$ & $637(7.4)$ & \\
\hline Mortality 30 days, No. (\%) & & & & $<0.001$ \\
\hline No & $4,559(96.5)$ & $3,809(97.8)$ & $8,368(97.1)$ & \\
\hline Yes & $167(3.5)$ & $87(2.2)$ & $254(2.9)$ & \\
\hline
\end{tabular}

$(\mathrm{P}=0.011)$, disseminated cancer $(\mathrm{P}=0.001)$, moderate dyspnea $(\mathrm{P}<0.001)$, and concurrent jejunostomy tube (OR $0.67 ; 0.51-0.88, \mathrm{P}=0.004)$ were independent predictors of 30-day mortality. Placement of a jejunostomy tube concurrent to esophagectomy resulted in a 33\% decreased risk of 30-day mortality.

Analysis of factors associated with prolonged hospital stay is listed in Table 4. Univariable analysis demonstrated that age $(\mathrm{P}=0.003)$, sex $(\mathrm{P}=0.044)$, COPD $(\mathrm{P}<0.001)$, ASA classification III $(\mathrm{P}=0.002)$, ASA classification IV $(\mathrm{P}<0.001)$, ASA classification $\mathrm{V}(\mathrm{P}<0.001)$, insulin-dependent diabetes $(\mathrm{P}=0.015)$, moderate dyspnea $(\mathrm{P}=0.005)$, dyspnea at rest $(\mathrm{P}=0.027)$, and concurrent jejunostomy tube placement
(OR $0.75 ; 0.60-0.92 ; \mathrm{P}=0.006)$ were associated with prolonged hospital stay. Multivariable analysis demonstrated that age $(\mathrm{P}=0.014)$, COPD $(\mathrm{P}=0.001)$, ASA classification III $(\mathrm{P}=0.017)$, ASA classification IV $(\mathrm{P}<0.001)$, ASA classification $\mathrm{V}(\mathrm{P}<0.001)$, cervical anastomosis $(\mathrm{P}=0.043)$, and concurrent jejunostomy tube (OR 0.78; 0.63-0.97; $\mathrm{P}=0.028)$ were independent predictors of prolonged hospital stay. Placement of a jejunostomy tube concurrent to esophagectomy resulted in a $22 \%$ decreased risk of a prolonged hospital stay mortality.

Analysis of factors associated with in-hospital mortality is listed in Table 5. Univariable analysis demonstrated that age $(\mathrm{P}<0.001)$, COPD $(\mathrm{P}<0.001)$, ASA classification 
Table 3 Univariate and multivariable logistic regression for 30-day mortality

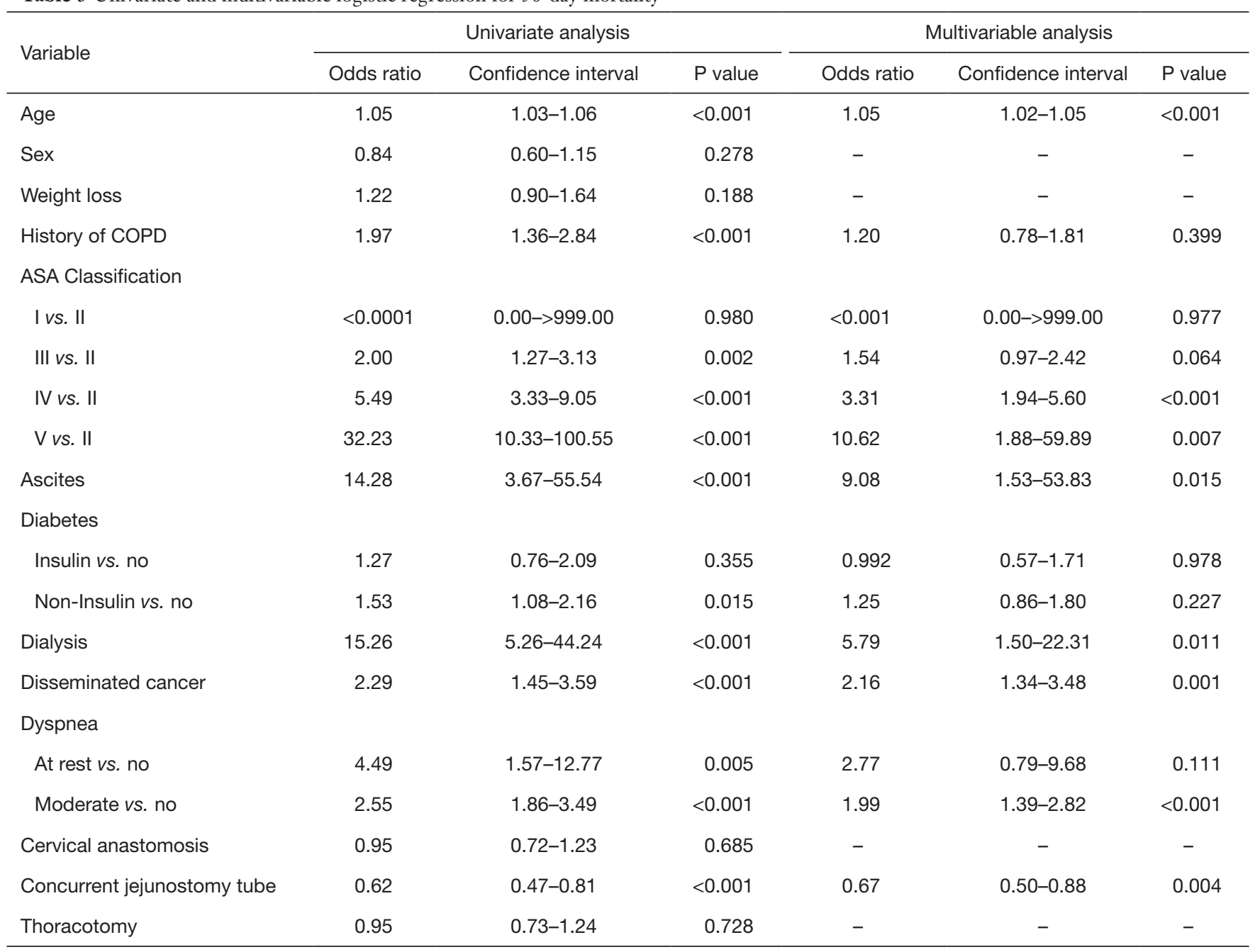

COPD, chronic obstructive pulmonary disease; ASA, American Society of Anesthesiologists.

III $(\mathrm{P}<0.001)$, ASA classification IV $(\mathrm{P}<0.001)$, ASA classification $\mathrm{V}(\mathrm{P}<0.001)$, ascites $(\mathrm{P}<0.001)$, dialysis $(\mathrm{P}<0.001)$, disseminated cancer $(\mathrm{P}<0.001)$, moderate dyspnea $(\mathrm{P}<0.0001)$, dyspnea at rest $(\mathrm{P}=0.001)$, non-insulindependent diabetes $(\mathrm{P}=0.01)$, insulin-dependent diabetes $(\mathrm{P}=0.008)$, and concurrent jejunostomy tube (OR 0.71; 0.60 $0.84 ; \mathrm{P}<0.001)$ were associated with in-hospital mortality. Multivariable analysis demonstrated that age $(\mathrm{P}<0.001)$, COPD $(\mathrm{P}=0.002)$, ASA classification III $(\mathrm{P}<0.001)$, ASA classification IV $(\mathrm{P}<0.001)$, ASA classification $\mathrm{V}(\mathrm{P}<0.001)$, ascites $(\mathrm{P}=0.022)$, dialysis $(\mathrm{P}=0.045)$, disseminated cancer $(\mathrm{P}=0.005)$, moderate dyspnea $(\mathrm{P}=0.006)$, and concurrent jejunostomy tube (OR $0.76 ; 0.64-0.90 ; \mathrm{P}=0.002)$ were independent predictors of in-hospital mortality. Placement of a jejunostomy tube concurrent to esophagectomy resulted in a $24 \%$ decreased risk of in-hospital mortality.

\section{Discussion}

Patients with esophageal cancer are at high risk for preoperative malnutrition due to tumor effect as well as esophageal tumor obstruction. $60 \%$ of hospitalized esophageal cancer patients are malnourished resulting in an increased risk for poor postoperative outcomes $(3,8,20,21)$. Nozoe et al. demonstrated that preoperative nutrition measured by the prognostic nutritional index (PNI) was an independent predictor of postoperative complications (20). Additionally, nutritional status of patients undergoing 
Table 4 Univariate and multivariable logistic regression for prolonged hospital stay ( $>30$ days)

\begin{tabular}{|c|c|c|c|c|c|c|}
\hline Variable & \multicolumn{3}{|c|}{ Univariate analysis } & \multicolumn{3}{|c|}{ Multivariable analysis } \\
\hline Age & 1.02 & $1.00-1.02$ & 0.003 & 1.01 & $1.00-1.02$ & 0.014 \\
\hline Sex & 1.28 & $1.00-1.63$ & 0.044 & 1.29 & $1.00-1.66$ & 0.054 \\
\hline Weight loss & 1.09 & $0.84-1.40$ & 0.509 & - & - & - \\
\hline \multicolumn{7}{|l|}{ ASA Classification } \\
\hline | vs. II & 1.72 & $0.22-13.23$ & 0.605 & 1.73 & $0.22-13.44$ & 0.598 \\
\hline III vs. II & 1.76 & $1.23-2.49$ & 0.002 & 1.55 & $1.07-2.21$ & 0.017 \\
\hline IV vs. II & 3.81 & $2.52-5.74$ & $<0.001$ & 2.97 & $1.92-4.60$ & $<0.001$ \\
\hline \multicolumn{7}{|l|}{ Diabetes } \\
\hline Insulin vs. no & 1.59 & $1.09-2.31$ & 0.015 & 1.46 & $0.98-2.15$ & 0.062 \\
\hline Non-insulin vs. no & 1.25 & $0.91-1.70$ & 0.162 & 1.26 & $0.91-1.72$ & 0.153 \\
\hline Dialysis & 3.56 & $0.76-16.5$ & 0.105 & - & - & - \\
\hline Disseminated cancer & 1.26 & $0.79-1.98$ & 0.320 & - & - & - \\
\hline \multicolumn{7}{|l|}{ Dyspnea } \\
\hline At rest vs. no & 3.38 & $1.14-9.93$ & 0.027 & - & - & - \\
\hline Moderate vs. no & 1.56 & $1.14-2.12$ & 0.005 & - & - & - \\
\hline
\end{tabular}

COPD, chronic obstructive pulmonary disease; ASA, American Society of Anesthesiologists.

neoadjuvant therapy or definitive chemoradiotherapy is prognostic, with an estimated $80 \%$ of patients experiencing malnutrition during therapy (22). For patients undergoing definitive radiotherapy, poor nutritional status [low nutritional risk index (NRI)] was an independent predictor of overall survival and disease-free survival (9).

Given the high prevalence of malnutrition and its deleterious effects for patients with esophageal cancer, there has been increasing focus on pre-treatment nutritional optimization. For patients at risk of malnutrition, use of a nutrition pathway was associated with less weight loss, greater therapy completion rates, reduced unplanned admission rates, and shorter length of stay (12). This nutrition pathway consisted of routine evaluation by a nutritionist with risk stratification of patients into "low", "moderate" or "severe" risk with oral nutritional support given to patients at "moderate" risk and gastrostomy tube placement for patients at "severe" risk before treatment (12). Insertion of an enteric tube for enteral feeding prior to multimodality therapy for esophageal cancer is associated with decreased weight loss, decreased hospital admissions for dehydration (11), increased completion rates of chemoradiotherapy, and overall survival (10).

In addition to preoperative nutritional optimization, perioperative nutrition is an important factor for patients with esophageal cancer undergoing esophagectomy. A prospective, randomized trial of patients undergoing surgical resection of upper GI malignancies comparing early enteral feeding to NPO with intravenous fluids demonstrated reduced length of stay, reduced operative 
Table 5 Univariate and multivariable logistic regression for in-hospital mortality

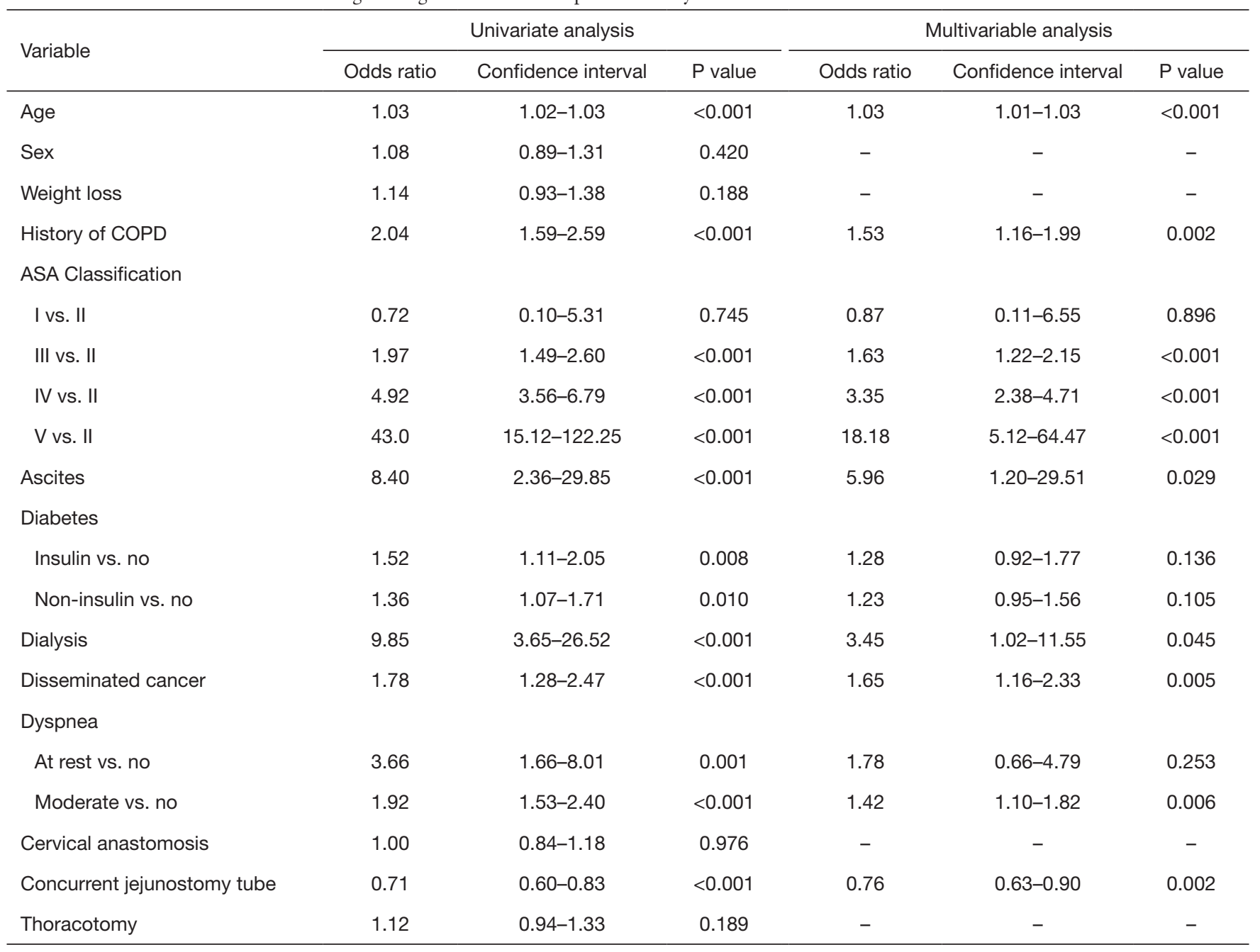

COPD, chronic obstructive pulmonary disease; ASA, American Society of Anesthesiologists.

morbidity, fewer wound infections, fewer chest infections, and fewer anastomotic leaks (23). A meta-analysis of fifteen studies of patients undergoing resectional gastrointestinal surgery demonstrated decreased complications for patients receiving early enteral feeding (24). In an analysis of the Surveillance Epidemiology and End Results-Medicare (SEER-Medicare) database, Lorimer et al. demonstrated that enteral feeding tubes are associated with improved short-term survival up to 90 days as well as shorter length of stay after esophagectomy (13).

There are multiple modalities for nutritional supplementation for patients after esophagectomy, including nasogastric tube, nasoduodenal tube, jejunostomy or parenteral nutrition via central venous port or peripherally inserted central catheter (PICC). While these different modalities can provide similar total nutrition, multiple studies have demonstrated the superiority of enteral feeding to parenteral nutrition (23-29). A meta-analysis of 29 trials, including 2,552 patients, evaluating enteral versus parenteral nutrition for patients undergoing gastrointestinal surgery demonstrated that enteral nutrition was associated with reduction in complication rates, infectious complications, anastomotic leak, intra-abdominal abscess, and length of stay (17). However, this meta-analysis was not specific to esophageal surgery. Peng et al. performed a metaanalysis of ten studies including 730 patients undergoing esophagectomy for esophageal cancer demonstrated that compared to parenteral feeding, enteral feeding was associated with decreased pulmonary complications and anastomotic leak as well as higher albumin and prealbumin 
levels (27). Nasoenteric tubes may be used to provide adequate nutritional supplementation, however 30-40\% of patients experience tube-associated complications such as dislodgement, accidental removal, and obstruction $(28,29)$. Jejunostomy tubes can provide enteric feeding in the preoperative and perioperative period without limiting reconstructive options at the time of esophagectomy (30).

Several retrospective series have examined the effects of jejunostomy placement at the time of esophagectomy. A retrospective study of nutritional support after esophagectomy from Spain compared 47 patients with feeding jejunostomy with 53 patients treated with parenteral nutrition. Thirty-day mortality was $4 \%$ overall and not broken down relative to group. Two patients suffered serious complications as a result of jejunostomy placement: One perforation and one case of peritonitis after tube dislodgement (31). A study from Japan used propensity matching among 393 patients undergoing esophagectomy to identify 139 undergoing jejunostomy placement and 139 who did not. Postoperative small bowel obstruction occurred more often $(12 \%$ vs. $0 \%)$ in the jejunostomy group. Median hospital stay was significantly longer in the jejunostomy group (30 vs. 18 days). Postoperative mortality was not reported (32). A similar study from Massachusetts General Hospital compared 135 patients with intraoperative jejunostomy tube to 53 patients treated without jejunostomy subsequent to a change in practice. Complications were noted in $7.4 \%$ of those treated with routine jejunostomy, including 3 operative procedures (2.2\%) (33).

Our analysis demonstrated that jejunostomy tube placement at the time of esophagectomy is associated with decreased rates of prolonged hospital stay, in-hospital mortality, and 30-day mortality. However, differences between the two groups existed including the presence and severity of dyspnea, presence of disseminated cancer, preoperative weight loss, cervical incision, thoracotomy, and location of anastomosis. These underlying differences in patient co-morbidities and surgical approach is indicative of a selection bias. In order to control for confounding factors, we performed analysis of factors associated with each of our outcome variables. Multivariable analysis demonstrated that concurrent jejunostomy tube placement is associated with a decreased risk of prolonged hospital stay, in-hospital mortality, and 30-day mortality.

This study had several limitations related to retrospective review of a data registry. Surgical outcomes are only tracked for 30 days and there is limited intermediate and longterm follow up data for patients. Additionally, oncologic data is not available for all patients; including tumor stage, lymph node harvest, and type of preoperative therapies. Also, the database did not include information regarding patients' previous procedures, therefore, we were unable to identify if patients had preoperative enteral tube placed prior to surgery. An inherent selection bias exists related to surgeons' decisions on which patients received concurrent jejunostomy tube placement. Lastly, we identified differences between groups and despite statistically controlling for these factors with multivariable analysis, there may be confounding factors that were not included in the database.

\section{Conclusions}

Placement of a jejunostomy tube at the time of esophagectomy is associated with significant decreases in rates of prolonged hospital stay, in-hospital mortality, and 30-day mortality. This study demonstrates that patients with concurrent jejunostomy placement at the time of esophagectomy have improved short term perioperative outcomes.

\section{Acknowledgments}

Funding: None.

\section{Footnote}

Conflicts of Interest: All authors have completed the ICMJE uniform disclosure form (available at http://dx.doi. org/10.21037/jgo.2020.02.06). The authors have no conflicts of interest to declare.

Ethical Statement: The authors are accountable for all aspects of the work in ensuring that questions related to the accuracy or integrity of any part of the work are appropriately investigated and resolved.

Open Access Statement: This is an Open Access article distributed in accordance with the Creative Commons Attribution-NonCommercial-NoDerivs 4.0 International License (CC BY-NC-ND 4.0), which permits the noncommercial replication and distribution of the article with the strict proviso that no changes or edits are made and the original work is properly cited (including links to both the formal publication through the relevant DOI and the license). See: https://creativecommons.org/licenses/by-nc- 
nd/4.0/.

\section{References}

1. Society AC. Key Statistics for Esophageal Cancer. American Cancer Society. Available online: https://www. cancer.org/cancer/esophagus-cancer/about/key-statistics. html. January 8, 2019.

2. American Cancer Society. Global Cancer Facts and Figures 4th Edition. American Cancer Society, editor. 2018.

3. Detsky AS, Baker JP, O'Rourke K, et al. Predicting nutrition-associated complications for patients undergoing gastrointestinal surgery. JPEN J Parenter Enteral Nutr 1987;11:440-6.

4. Klek S, Sierzega M, Szybinski P, et al. Perioperative nutrition in malnourished surgical cancer patients - a prospective, randomized, controlled clinical trial. Clin Nutr 2011;30:708-13.

5. Han-Geurts IJ, Hop WC, Tran TC, et al. Nutritional status as a risk factor in esophageal surgery. Dig Surg 2006;23:159-63.

6. Kight CE. Nutrition considerations in esophagectomy patients. Nutr Clin Pract 2008;23:521-8.

7. Waitzberg DL, Caiaffa WT, Correia MI. Hospital malnutrition: the Brazilian national survey (IBRANUTRI): a study of 4000 patients. Nutrition 2001;17:573-80.

8. Bozzetti F, Mariani L, Lo Vullo S, et al. The nutritional risk in oncology: a study of 1,453 cancer outpatients. Support Care Cancer 2012;20:1919-28.

9. Clavier JB, Antoni D, Atlani D, et al. Baseline nutritional status is prognostic factor after definitive radiochemotherapy for esophageal cancer. Dis Esophagus 2014;27:560-7.

10. Margolis M, Alexander P, Trachiotis GD, et al. Percutaneous endoscopic gastrostomy before multimodality therapy in patients with esophageal cancer. Ann Thorac Surg 2003;76:1694-7; discussion 1697-8.

11. Piquet MA, Ozsahin M, Larpin I, et al. Early nutritional intervention in oropharyngeal cancer patients undergoing radiotherapy. Support Care Cancer 2002;10:502-4.

12. Odelli C, Burgess D, Bateman L, et al. Nutrition support improves patient outcomes, treatment tolerance and admission characteristics in oesophageal cancer. Clin Oncol (R Coll Radiol) 2005;17:639-45.

13. Lorimer PD, Motz BM, Watson M, et al. Enteral Feeding Access Has an Impact on Outcomes for Patients with Esophageal Cancer Undergoing Esophagectomy:
An Analysis of SEER-Medicare. Ann Surg Oncol 2019;26:1311-9.

14. Fujita T, Daiko H, Nishimura M. Early enteral nutrition reduces the rate of life-threatening complications after thoracic esophagectomy in patients with esophageal cancer. Eur Surg Res 2012;48:79-84.

15. Heslin MJ, Latkany L, Leung D, et al. A prospective, randomized trial of early enteral feeding after resection of upper gastrointestinal malignancy. Ann Surg 1997;226:567-77; discussion 577-80.

16. Takesue T, Takeuchi H, Ogura M, et al. A Prospective Randomized Trial of Enteral Nutrition After Thoracoscopic Esophagectomy for Esophageal Cancer. Ann Surg Oncol 2015;22 Suppl 3:S802-9.

17. Mazaki T, Ebisawa K. Enteral versus parenteral nutrition after gastrointestinal surgery: a systematic review and meta-analysis of randomized controlled trials in the English literature. J Gastrointest Surg 2008;12:739-55.

18. Weijs TJ, Berkelmans GH, Nieuwenhuijzen GA, et al. Immediate Postoperative Oral Nutrition Following Esophagectomy: A Multicenter Clinical Trial. Ann Thorac Surg 2016;102:1141-8.

19. User Guide for the 2007 Participant Use Data File. American College of Surgeons National Surgical Quality Improvement Program. [database on the Internet]2008. Available online: https://www.facs.org/ /media/files/ quality\%20programs/nsqip/ug07.ashx

20. Nozoe T, Kimura Y, Ishida M, et al. Correlation of preoperative nutritional condition with post-operative complications in surgical treatment for oesophageal carcinoma. Eur J Surg Oncol 2002;28:396-400.

21. Hebuterne X, Lemarie E, Michallet M, et al. Prevalence of malnutrition and current use of nutrition support in patients with cancer. JPEN J Parenter Enteral Nutr 2014;38:196-204.

22. Pan P, Tao G, Sun X. Subjective global assessment and prealbumin levels of esophageal cancer patients undergoing concurrent chemoradiotherapy. Nutr Hosp 2015;31:2167-73.

23. Barlow R, Price P, Reid TD, et al. Prospective multicentre randomised controlled trial of early enteral nutrition for patients undergoing major upper gastrointestinal surgical resection. Clin Nutr 2011;30:560-6.

24. Osland E, Yunus RM, Khan S, et al. Early versus traditional postoperative feeding in patients undergoing resectional gastrointestinal surgery: a meta-analysis. JPEN J Parenter Enteral Nutr 2011;35:473-87.

25. Gabor S, Renner H, Matzi V, et al. Early enteral feeding 
compared with parenteral nutrition after oesophageal or oesophagogastric resection and reconstruction. Br J Nutr 2005;93:509-13.

26. Park JS, Chung HK, Hwang HK, et al. Postoperative nutritional effects of early enteral feeding compared with total parental nutrition in pancreaticoduodectomy patients: a prosepective, randomized study. J Korean Med Sci 2012;27:261-7.

27. Peng J, Cai J, Niu ZX, et al. Early enteral nutrition compared with parenteral nutrition for esophageal cancer patients after esophagectomy: a meta-analysis. Dis Esophagus 2016;29:333-41.

28. Han-Geurts IJ, Hop WC, Verhoef C, et al. Randomized clinical trial comparing feeding jejunostomy with nasoduodenal tube placement in patients undergoing oesophagectomy. Br J Surg 2007;94:31-5.

29. Torres Junior LG, de Vasconcellos Santos FA, Correia MI. Randomized clinical trial: nasoenteric tube or jejunostomy as a route for nutrition after major upper gastrointestinal

Cite this article as: Watson M, Trufan S, Benbow JH, Gower NL, Hill J, Salo JC. Jejunostomy at the time of esophagectomy is associated with improved short-term perioperative outcomes: analysis of the NSQIP database. J Gastrointest Oncol 2020;11(2):421-430. doi: 10.21037/jgo.2020.02.06 operations. World J Surg 2014;38:2241-6.

30. Ohnmacht GA, Allen MS, Cassivi SD, et al. Percutaneous endoscopic gastrostomy risks rendering the gastric conduit unusable for esophagectomy. Dis Esophagus 2006;19:311-2.

31. Alvarez-Sarrado E, Mingol Navarro F, J Rosellón R, et al. Feeding Jejunostomy after esophagectomy cannot be routinely recommended. Analysis of nutritional benefits and catheter-related complications. Am J Surg 2019;217:114-20.

32. Koterazawa Y, Oshikiri T, Hasegawa H, et al. Routine placement of feeding jejunostomy tube during esophagectomy increases postoperative complications and does not improve postoperative malnutrition. Dis Esophagus 2020. doi: 10.1093/dote/doz021.

33. Kroese TE, Tapias L, Olive JK, et al. Routine intraoperative jejunostomy placement and minimally invasive oesophagectomy: an unnecessary step?dagger. Eur J Cardiothorac Surg 2019;56:746-53. 